\title{
The validity and reliability of a home environment preschool-age physical activity questionnaire (Pre-PAQ)
}

\author{
Genevieve M Dwyer ${ }^{1,2^{*}}$, Louise L Hardy ${ }^{3 \dagger}$, Jennifer K Peat ${ }^{4 \dagger}$ and Louise A Baur ${ }^{2,3 \dagger}$
}

\begin{abstract}
Background: There is a need for valid population level measures of physical activity in young children. The aim of this paper is to report the development, and the reliability and validity, of the Preschool-age Children's Physical Activity Questionnaire (Pre-PAQ) which was designed to measure activity of preschool-age children in the home environment in population studies.

Methods: Pre-PAQ was completed by 103 families, and validated against accelerometry for 67 children (mean age 3.8 years, SD 0.74; males 53\%). Pre-PAQ categorizes activity into five progressive levels (stationary no movement, stationary with limb or trunk movement, slow, medium, or fast-paced activity). Pre-PAQ Levels 1-2 (stationary activities) were combined for analyses. Accelerometer data were categorized for stationary, sedentary (SED), nonsedentary (non-SED), light (LPA), moderate (MPA) and vigorous (VPA) physical activity using manufacturer's advice (stationary) or the cut-points described by Sirard et al and Reilly et al. Bland-Altman methods were used to assess agreement between the questionnaire and the accelerometer measures for corresponding activity levels. Reliability of the Pre-PAQ over one week was determined using intraclass correlations (ICC) or kappa $(\kappa)$ values and percentage of agreement of responses between the two questionnaire administrations.

Results: Pre-PAQ had good agreement with LPA (mean difference 1.9 mins.day ${ }^{-1}$ ) and VPA (mean difference -4.8 mins.day ${ }^{-1}$ ), was adequate for stationary activity (mean difference 7.6 mins.day ${ }^{-1}$ ) and poor for sedentary activity, whether defined using the cut-points of Sirard et al (mean difference -235.4 mins.day ${ }^{-1}$ ) or Reilly et al (mean difference -208.6 mins.day ${ }^{\top 1}$ ) cut-points. Mean difference between the measures for total activity (i.e. Reilly's nonsedentary or Sirard's LMVPA) was 20.9 mins.day $^{-1}$ and 45.2 mins.day $^{-1}$. The limits of agreement were wide for all categories. The reliability of Pre-PAQ question responses ranged from 0.31-1.00 (ICC $(2,1))$ for continuous measures and 0.60-0.97 $(\kappa)$ for categorical measures.

Conclusions: Pre-PAQ has acceptable validity and reliability and appears promising as a population measure of activity behavior but it requires further testing on a more broadly representative population to affirm this. Pre-PAQ fills an important niche for researchers to measure activity in preschool-age children and concurrently to measure parental, family and neighborhood factors that influence these behaviors.
\end{abstract}

\section{Background}

Physical activity is a pre-requisite for optimal growth and development in children and is also important in the prevention of chronic diseases [1-3]. In older children, physical inactivity and increasing patterns of

\footnotetext{
* Correspondence: genevieve.dwyer@sydney.edu.au

† Contributed equally

'Discipline of Physiotherapy, University of Sydney, Box 170 Lidcombe NSW

1825, Australia

Full list of author information is available at the end of the article
}

sedentary behavior contribute to the development of overweight and obesity and its adverse health sequelae [4]. However less is known about activity behavior of very young children because there are limited tools for the measurement of physical activity and/or sedentary behavior in this age group [5-7].

No single assessment method can measure all the domains of physical activity and/or sedentary behavior [8]. Each assessment method, whether subjective or objective, has advantages and disadvantages. 
Questionnaires are utilized in large-scale population surveys because of relatively lower costs and participant burden [9]. There is a need for a specific questionnaire to assess activity behavior in preschool-age children [5,6]. In this age group a proxy-report tool is necessary as young children lack the cognitive capacity to assess or recall their activity $[10,11]$. The Preschool-age Children's Physical Activity Questionnaire (Pre-PAQ) was developed to fill this niche. Specifically it was developed to measure population estimates of activity in young children in their home environment. The aims of this paper are to outline the development and socioecological framework of Pre-PAQ, and to report its validity and reliability in preschool-aged children (3-5 years).

\section{Materials and methods Development of Pre-PAQ}

The development of Pre-PAQ involved five strategies: (i) review of the literature; (ii) examination of existing, validated, physical activity questionnaires; (iii) consulting physical activity experts from the Australasian Child and Adolescent Obesity Research Network [12]; (iv) conducting focus groups with parents and preschool staff to assess the content and face validity of questionnaire items; and (v) pilot testing.

Pre-PAQ is a 3-day activity questionnaire designed to measure habitual physical activity and sedentary behavior in the child's home environment. Pre-PAQ has been designed under the premise that there are multidimensional influences upon young children's behavior, reflecting a socioecological framework [13-15]. The questionnaire has items related to these potential influences including: (i) parent physical activity and parenting habits and attitudes; (ii) family demographics; (iii) home and neighborhood environment; and (iv) the child's inherent activity nature (see Additional file 1: Pre-PAQ Questionnaire for complete questionnaire). A recall approach was used, in the questionnaire design, to lessen the chance that recording may alter parental activity behavior or the manner in which parents encourage their child's behavior [16].

Assessment of the child's physical activity (one week day and two weekend days) included a list of activities typical in preschool children with a response of 'Yes' or 'No' and, if 'Yes', the time the child spent in that activity. Both weekend days were included in the questionnaire as earlier parent focus groups (run as part of a different study) had indicated that activity routines at home varied more on a weekend than week days. In addition, information was attained on whether the child participated in organized activity during the week. Parents reported type of activity, duration spent in the activity and the number of times usually spent in the activity each week. Other information included how long the child spent outdoors and weather conditions on the monitored days as these are recognized influences on activity behavior $[17,18]$.

\section{Defining levels of activity}

The questions related to the child's activity were classified using the Child Activity Rating Scale (CARS) $[19,20]$ as a basis. That is, activity is classified as one of five progressive levels: completely stationary, stationary but moving a limb or the trunk, moving slowly, moving at a moderate pace, or moving quickly (see Table 1). The stationary activities of television viewing, watching DVDs, using the computer, and lying still while reading or being read to, were separated in order to identify the time spent in specific small screen recreation (SSR) activities. Time the child spent travelling in a car was also reported and included in assessment of stationary activity time (i.e. Pre-PAQ Level 1).

We hypothesised that estimates of physical activity from Pre-PAQ data would demonstrate an adequate level of agreement with estimates of activity from accelerometer data, at a group summary level, and accepted that there would be differences between the two measures because the estimates were being derived from tools with different properties. As noted above, PrePAQ is designed as a 3-day recall questionnaire whereas accelerometer data are generally collected at 15-second to 1 -minute sampling rates. Clearly, human memory cannot match this level of precision. Further, accelerometers measure incidental movement (or sedentary activity) that would not be registered as a meaningful bout of activity to an observer e.g. child moving around the home environment as part of daily routines such as walking to the bathroom, or when standing and talking with their parent. We considered an a priori adequate level of agreement to be within 30 minutes per day for sedentary level of activity, 15 minutes per day for slowpaced activity, 10 minutes per day for medium-paced activity, and 5 minutes per day for fast-paced activity, and 30 minutes per day for total activity.

\section{Participants}

For estimating agreement between two continuously distributed variables (in this instance estimates of time measured by Pre-PAQ and accelerometry), a sample size of 100 participants gives good precision [[21], p143]. A convenience sample of 105 participant dyads (preschoolage child and their parent/guardian) were recruited via advertisements distributed to preschools statewide and within the authors' hospital and university intranet systems, and from contacts that snowballed from these strategies. Children age 3.0 to 5.9 years who had not yet commenced formal schooling were eligible to participate. Exclusion criteria were a recognized disability (physical, emotional/behavioral or intellectual) that 
Table 1 Levels of physical activity measured by Pre-PAQ

\begin{tabular}{|c|c|c|}
\hline $\begin{array}{l}\text { Activity } \\
\text { Level }\end{array}$ & Description & Type of activity \\
\hline Level 1 & Stationary - no movement & $\begin{array}{l}\text { Sat or lay still watching TV } \\
\text { Sat or lay still watching DVD or a video } \\
\text { Sat or lay still (e.g. looking at books or listening to stories) }\end{array}$ \\
\hline Level 2 & $\begin{array}{l}\text { Stationary - limb or trunk } \\
\text { moving }\end{array}$ & $\begin{array}{l}\text { Was stationary but swinging or swaying trunk (e.g. standing and singing a song) } \\
\text { Was stationary but moving arm or leg (e.g. sitting doing puzzles or craft, digging in a sandpit or } \\
\text { standing and kicking or throwing a ball) } \\
\text { Played computer or electronic games }\end{array}$ \\
\hline Level 3 & Moving slowly & $\begin{array}{l}\text { Walked at a leisurely or moderate pace } \\
\text { Hopped, jumped, skipped or marched at an easy pace } \\
\text { Used swing (moving self - not being pushed by another person) } \\
\text { Rode a tricycle, bike or scooter etc. at an easy pace or slow speed } \\
\text { Swam with support of an adult }\end{array}$ \\
\hline Level 4 & $\begin{array}{l}\text { Moving at a medium or } \\
\text { moderate pace }\end{array}$ & $\begin{array}{l}\text { Walked at a fast pace } \\
\text { Ran or jogged slowly } \\
\text { Rough and tumble play with moderate effort } \\
\text { Hopped, jumped, skipped or marched at an moderate speed or effort } \\
\text { Danced or did movement and music activities (moving around) } \\
\text { Climbed (e.g. on play equipment, in a tree etc.) } \\
\text { Rode a tricycle, bike or scooter etc. at an moderate pace or medium speed } \\
\text { Swam by self ( } \pm \text { floatation devices) }\end{array}$ \\
\hline Level 5 & Moving at a fast pace & $\begin{array}{l}\text { Walked up steep slopes } \\
\text { Ran or jogged quickly } \\
\text { Rough and tumble play with hard effort } \\
\text { Hopped, jumped, skipped or marched at an fast speed or effort } \\
\text { Rode a tricycle, bike or scooter etc. at an hard pace or fast speed }\end{array}$ \\
\hline
\end{tabular}

${ }^{1}$ Swimming activities were excluded from analyses as the child did not wear the accelerometer during this period of time.

would affect participation in physical activity and inadequate English proficiency of parents/guardians to complete the questionnaire. Informed consent was obtained from the child's parent and the study was approved by the Human Research Ethics Committees of The Children's Hospital at Westmead and The University of Sydney.

The study was conducted from December 2007 to December 2008. Prior to data collection families were visited at home or at their child's preschool. Field staff oriented the parent to the questionnaire, and demonstrated how to fit the accelerometer by using a belt and positioning the device over the child's right hip. Data collection occurred in the child's home environment corresponding to the 3-day period when the child was at home with their parent or carer.

\section{Reliability}

To measure the test-retest reliability of the questionnaire, parents were asked to complete Pre-PAQ on two separate occasions one to two weeks apart. Reminder telephone calls, emails and/or SMS messages were used to assist with timely completion of both questionnaires.

\section{Criterion validity}

Parents self-selected whether their child would wear an accelerometer for the period corresponding to the first administration of the questionnaire. Uni-axial MTI 7164
Actigraph motion sensors (MTI Health Services, Fort Walton Beach, FL) were used. This device has established reliability and validity in preschool-age children [22]. The devices were initialized with a 15-second sampling epoch to capture the sporadic pattern of activity in this age group [23]. Using this sampling time frame, the memory storage of the device permitted a maximum of five days data collection. Parents were asked to fit the accelerometer on their child each day during their wake time except if bathing or swimming. Children wore the accelerometer for 4-5 days with the first day's data excluded from the analyses to eliminate any reactivity to wearing the device. The variation in time wearing the accelerometer (that is, 4 or 5 days) reflected the selected weekday the child was at home with their parent, and weekend being monitored.

Accelerometer data were downloaded to a PC using the MTI Windows Actigraph software (http://www. theactigraph.com). Each file was inspected to screen the wearing pattern and ensure that the device had functioned properly. Compliance was monitored by checking for consecutive strings (20 minutes) of zero counts that were not explained by parent log of when the device had been removed (for example day time sleep or water activities) [22,24].

Only the children who wore the accelerometer for the three monitored days and who had at least six hours of recorded activity were included in the validity analyses. 
This approach aligns with methodological considerations advocated by Cliff et al [22]. These criteria excluded 21 children.

Time spent in activity of specific levels of intensity was estimated using cut-points described by (a) Sirard at al [25] for sedentary (SED), light physical activity (LPA), moderate physical activity (MPA) and vigorous physical activity (VPA) in 3, 4 and 5 year old children; and (b) Reilly et al [26] for sedentary and non-sedentary activity. These cut-points were selected as they had been derived specifically for preschool-age children and were based upon empirical relationships between accelerometry and direct observation (a gold standard activity measure). In order to identify stationary time, the accelerometer data were also analyzed using the cut-point $0-20$ as a conservative estimate of the child being completely stationary, based upon advice of the device manufacturer. This choice of cut-point is supported by the findings of a subsequent study published by Krishnaveni et al [27]. In their study of preschool-age children they noted a range of $0-3$ counts per minute for passive sitting, which would equate to a stationary activity.

Questionnaire data were entered into an Access database. Accelerometer measures were assessed for the 10hour period between 0800 and 1800 as this time frame reflected the common wear time of the accelerometer by most participants. If the total activity reported on the questionnaire exceeded 10 hours these participants $(\mathrm{n}=$ 9) were removed from the criterion validity analyses.

\section{Statistical analysis}

Data were analyzed using Statistical Package for the Social Sciences (SPSS) (Version 17 SPSS Inc., Chicago IL). MedCalc Statistical Software (Version 10.4, MedCalc Software, Mariarke, Belgium) was used for Bland-Altman tests of agreement. Tests of normality were undertaken and where data were non-normally distributed, nonparametric tests were used (kappa or Spearman's rank correlation).

\section{Descriptive analyses}

A three-day mean was calculated for each level of activity (minutes.day ${ }^{-1}$ ) recorded by the accelerometer, and reported by the parent. Stationary levels in the questionnaire (Pre-PAQ Levels 1-2) were summed for comparison with stationary and sedentary behavior levels from the accelerometer-derived data. Pre-PAQ stationary levels included reported time spent in the car as the accelerometer was worn during this activity. Time spent in water activities was excluded because the accelerometer was not worn at such times.

\section{Reliability analyses}

The reliability between the two administrations of PrePAQ was measured by the consistency of the item responses in the sections relating to parental report of their own and their partner's activity behavior, parenting attitudes and behaviors, pattern of car usage and active transport, facilities in the home and neighborhood environment, perceptions about the neighborhood, perceptions about the child's activity nature, reporting of the child's activity (free, unstructured activity as well as organized activity) and meal-time habits.

Reliability was assessed using intra-class correlation (ICC) for continuous variables and kappa $(\kappa)$ values for categorical variables. Percent agreement of responses between the two administrations was also calculated. Interpretation of reliability was taken as $<0.20$ represents poor agreement, 0.21-0.40 represents fair agreement, 0.41-0.60 represents moderate agreement, 0.610.80 represents good agreement and 0.81-1.00 equals very good agreement [[28], p404].

\section{Validity analyses}

Levels of agreement between parental reports of the child's activity time and the accelerometer (which was regarded as the 'gold standard') were analyzed as described by Bland and Altman [29]. Levels of agreement were assessed between the two measures for stationary, sedentary, light, moderate, moderate-vigorous, and light-moderate-vigorous physical (or non-sedentary) activity. Differences vs. means plots were used to assess bias between parent report of the child's activity time and accelerometer measurement.

Pearson's correlation was used to compare our findings with published validity studies, although we note the value of this statistic in estimating agreement between two measures has been questioned $[29,30]$. Correlations may be high but the measures may not necessarily agree and so this statistic may be misleading [29].

\section{Results}

\section{Participants}

Participant characteristics are shown in Table 2. The mean age of the children was 3.8 years, (SD 0.74), 87\% were Caucasian and $53 \%$ were male. The parent respondent was principally the mother (92\%). Of 105 families, $95 \%$ used the accelerometer. However, some children did not wear the accelerometer for the required time which resulted in different numbers of participants in the validity and reliability analyses (see Figure 1). The mean accelerometer wearing time was 9.2 hours.day $^{-1}$ (SD 0.79).

Physical activity data from Pre-PAQ and the accelerometer (3-day mean: mins.hr ${ }^{-1}$ ) are shown in Table 3. There were no significant differences between age groups or sexes for activity levels measured by either Pre-PAQ (Age difference: $\mathrm{F}=1.14, \mathrm{df}=2,92, P=0.32$, Sex difference: $\mathrm{F}=0.01, \mathrm{df}=1,93, P=0.92$ ) or the accelerometer (Age difference: $\mathrm{F}=1.02, \mathrm{df}=2,73, P=$ 


\begin{tabular}{|c|c|c|}
\hline & Reliability study (n) & Validity study (n) \\
\hline Children & 103/105 enrolled & $67 / 105$ enrolled \\
\hline Boys & $54(52 \%)$ & $35(52 \%)$ \\
\hline \multicolumn{3}{|l|}{ Ages } \\
\hline 3 year olds & $37(36 \%)$ & $18(27 \%)$ \\
\hline 4 year olds & $46(45 \%)$ & $33(49 \%)$ \\
\hline 5 year olds & 20 (19\%) & $16(24 \%)$ \\
\hline Parents & 103 & 67 \\
\hline Relationship to child: mother & 95 (92\%) & $63(94 \%)$ \\
\hline \multicolumn{3}{|l|}{ Socioeconomic status ${ }^{1}$} \\
\hline Low & $7(7 \%)$ & $6(9 \%)$ \\
\hline Middle & $30(29 \%)$ & $23(34 \%)$ \\
\hline High & $66(64 \%)$ & $38(57 \%)$ \\
\hline \multicolumn{3}{|l|}{ Ethnicity } \\
\hline White (Anglo-Celtic) & 90 (87\%) & $61(91 \%)$ \\
\hline Mediterranean & $6(6 \%)$ & $2(3 \%)$ \\
\hline Other ethnicity & $7(7 \%)$ & $4(6 \%)$ \\
\hline \multicolumn{3}{|l|}{ Mother's education level } \\
\hline Completed high school & $10(11 \%)$ & $9(14 \%)$ \\
\hline Apprenticeship/university & 85 (89\%) & $54(86 \%)$ \\
\hline \multicolumn{3}{|c|}{ Marital status of parent completing Pre-PAQ } \\
\hline Married/living with partner & $96(93 \%)$ & $64(95 \%)$ \\
\hline Single & $7(7 \%)$ & $3(5 \%)$ \\
\hline
\end{tabular}

${ }^{1}$ SES based upon residential postcode using the Australian Bureau of Statistics Socio-Economic Indexes for Areas (SEIFA) Index of Relative Socioeconomic Disadvantage (45) organised into tertiles.

0.37, Sex difference: $\mathrm{F}=0.34, \mathrm{df}=1,74, P=0.56)$ and therefore data were analyzed as one group.

\section{Reliability of Pre-PAQ}

The reliability of the items in the Pre-PAQ ranged from 0.31-1.00 (ICC $(2,1)$ ) and 0.60-0.97 ( $\kappa)$ (Table 4). Items with lowest reliability were time the child was in the car on a weekend (Saturday: ICC $(2,1)$ : 0.37 ; Sunday: ICC $(2,1): 0.31)$ and parental time spent in MPA on a weekend (ICC $(2,1): 0.53)$. Measurement error of parental activities ranged from 3.7 minutes for time spent in MPA during the week to 9.0 minutes for time spent in VPA during the weekend. Measurement error for reporting of parental screen time recreation (STR) ranged from 5.5 minutes for time spent on the computer on a weekend to 13.8 minutes for time spent watching television during the week. Parental STR activities represented time the parent spent using the computer for recreation, watching television, videos or DVDs, or playing electronic games.

There was moderate to good agreement in the reporting of the child' activity with variations from an ICC (2, 1) of 0.44 (time child spent in stationary activities and time child spent in moderately-paced activities) to an ICC $(2,1)$ of 0.64 (time child spent in fast-paced activities). Agreement of time child spent in organized activities was very good (ICC $(2,1)$ : 0.96-0.99) and measurement error of time child spent in organized activities ranged from 1.0-1.1 minutes. Agreement in other parental and child activities is shown in Table 4.

Items related to parenting behaviors and attitudes (ICC $(2,1): 0.89-0.93)$, perception of the neighborhood ( $\kappa: 0.60-0.90$, \% agreement: 78.0-99.1), presence of small screen recreation items in the household (ICC $(2,1)$ : 0.96-1.0) and perception of the child's physical activity nature (ICC $(2,1)$ : 0.87-0.93) had good to very good agreement between the two administrations of the questionnaire.

\section{Validity of Pre-PAQ}

Table 5 summarizes the agreement between reported activity time from the first questionnaire and the accelerometer data for the 67 children who met the inclusion criteria. Agreement was highest between Pre-PAQ Level 5 and VPA (mean difference, 1.9 mins. day $^{-1}$ ) and PrePAQ Level 3 and LPA (mean difference, -4.8 mins.day ${ }^{-}$ ${ }^{1}$ ). However the $95 \%$ limits of agreement (LoA) were wide ( -37.5 to 41.3 mins.day ${ }^{-1}$ and -105.5 to 96.0 mins. day $^{-1}$, respectively).

Level of agreement in assessing total activity (Pre-PAQ Levels 3-5 and LMVPA or non-sedentary activity) was closer when Reilly at al's cut-points were used to define the accelerometer data (mean difference 20.9 mins.day ${ }^{-}$ ${ }^{1}$ ). When Sirard et al's cut-points were used the mean 


\section{Validity procedure}

\section{Reliability procedure}
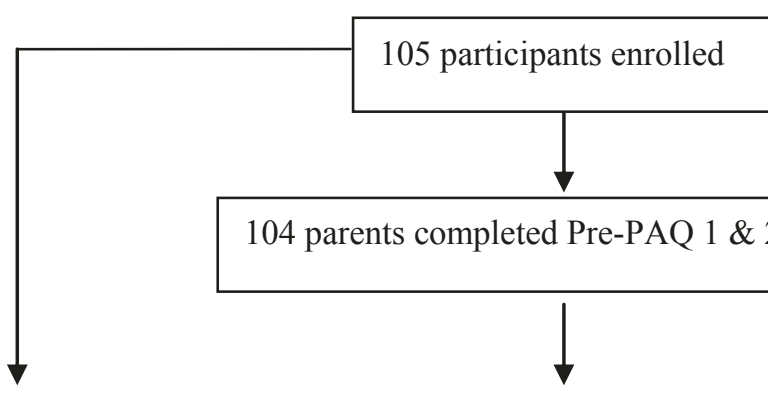

104 parents completed Pre-PAQ $1 \& 2$

No accelerometer data $\mathrm{n}=21^{1}$

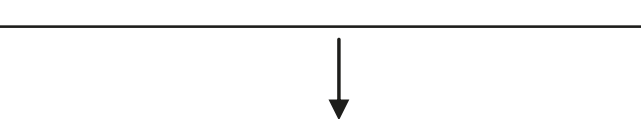

1 excluded:

Mother completed Pre-PAQ-1

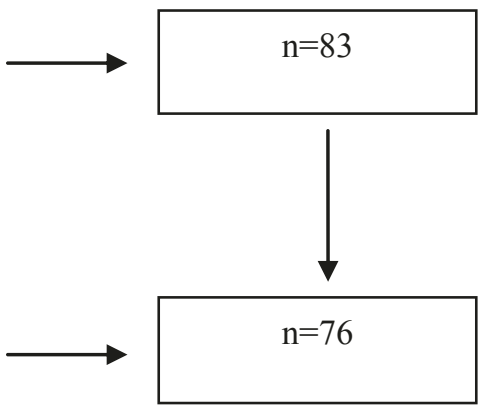

Father completed Pre-PAQ-2

7 excluded:

$<3$ hours of accelerometer data on one day $(\mathrm{n}=1)$

$>24$ hours of activity reported on a single day $(\mathrm{n}=1)$

Child reported as only being stationary $(n=3)$

Outliers on reported activity in

Pre-PAQ Levels 4-5 (n=2)

9 excluded:

$>600$ mins of activity reported
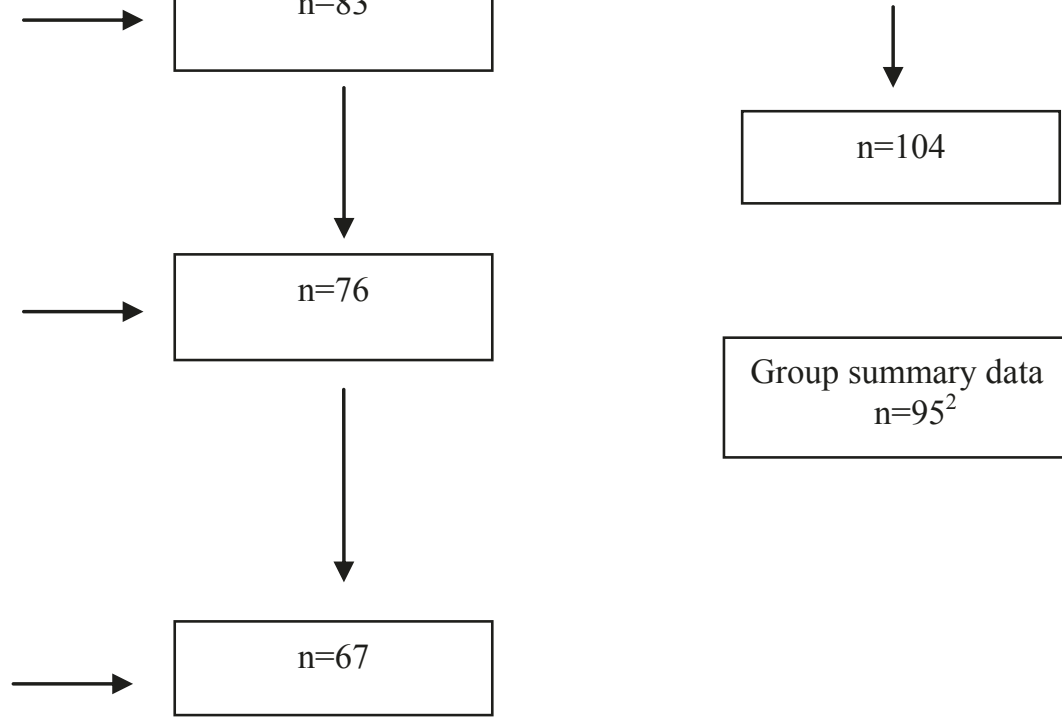

Group summary data $\mathrm{n}=95^{2}$

\footnotetext{
${ }^{1}$ The parents of three children who had no accelerometer data had reported their child as only being stationary on one of the monitored days and so these children were not included in summary data of the children's physical activity.

${ }^{2} \mathrm{n}=104-9$ exclusions of children with questionable reporting of physical activity on Pre-PAQ-1
}

Figure 1 Study design

Table 3 Activity levels measured by Pre-PAQ and accelerometry

\begin{tabular}{|c|c|c|c|c|c|}
\hline \multicolumn{2}{|c|}{ Pre-PAQ } & \multicolumn{4}{|c|}{ Accelerometer } \\
\hline Pre-PAQ level & $\begin{array}{l}\text { 3-Day mean } \\
(\text { mins.hr-1) }\end{array}$ & Accelerometer categorisation & $\begin{array}{l}\text { 3-Day mean } \\
(\text { mins.hr-1) }\end{array}$ & $\begin{array}{l}\text { 3-Day mean } \\
\text { (mins.hr-1) } \\
\text { (Reilly cut-points) }\end{array}$ & $\begin{array}{l}\text { 3-Day mean } \\
\text { (mins.hr-1) } \\
\text { (Sirard cut-points) }\end{array}$ \\
\hline Level 1-2 & $37.1(34.4,39.7)$ & Stationary & $24.6(\mathrm{Cl}: 23.5,25.6)$ & & \\
\hline Level 1-2 & $37.1(34.4,39.7)$ & Sedentary (SED) & & 46.3 (Cl: 45.4, 47.1) & 48.9 (Cl: 48.0, 49.6) \\
\hline Level 3 & $9.7(\mathrm{Cl}: 8.0,11.3)$ & LPA & & & $7.1(\mathrm{Cl}: 6.6,7.5)$ \\
\hline Level 4 & 10.6 (Cl: 9.3, 11.9) & MPA & & & $2.4(\mathrm{Cl}: 2.1,2.7)$ \\
\hline Level 5 & $2.6(\mathrm{Cl}: 2.0,3.4)$ & VPA & & & $1.6(\mathrm{Cl}: 1.3,1.9)$ \\
\hline Level 4-5 & $13.3(\mathrm{Cl}: 11.6,14.9)$ & MVPA & & & $4.1(\mathrm{Cl}: 3.6,4.6)$ \\
\hline Level 3-5 & 22.9 (Cl: 20.5, 25.4) & Non-SED/LMVPA & & 13.7 (Cl: 12.9, 14.6) & $11.2(\mathrm{Cl}: 10.3,12.0)$ \\
\hline
\end{tabular}


Table 4 Reliability of Pre-PAQ

\begin{tabular}{|c|c|c|c|}
\hline Section and item & Measurement scale & $\begin{array}{l}\text { ICC } \\
\text { (range) }\end{array}$ & $\begin{array}{l}\text { Kappa } \\
\text { (range) }\end{array}$ \\
\hline \multicolumn{4}{|l|}{ Parent } \\
\hline (1) Physical activity behaviour (Monday-Friday, Weekend) & Mins.day ${ }^{-1}$ & $0.53-0.92$ & \\
\hline (2) Television viewing (Monday-Friday, Weekend) & Mins.day ${ }^{-1}$ & $0.70-0.88$ & \\
\hline (3) Computer time (Monday-Friday, Weekend) & Mins.day ${ }^{-1}$ & $0.82-0.85$ & \\
\hline (4) Parenting behaviours & 9-point Likert scale & $0.89-0.93$ & \\
\hline \multicolumn{4}{|l|}{ Family } \\
\hline (1) Car use (over a typical week) & 4-point Likert scale & & 0.97 \\
\hline (2) Time child spent in car (Weekday, Saturday, Sunday) & Mins.day ${ }^{-1}$ & $0.31-0.63$ & \\
\hline \multicolumn{4}{|l|}{ Home and Neighborhood } \\
\hline (1) Perception of neighborhood & One of four categories & & $0.60-0.90$ \\
\hline (2) Home small screen recreation items & Number of items & $0.96-1.00$ & \\
\hline \multicolumn{4}{|l|}{ Child } \\
\hline (1) Child's activity nature & 9-point Likert scale & $0.87-0.93$ & \\
\hline (2) Involvement in organised activities & Dichotomous (yes/no) & & 0.95 \\
\hline (3) Use of neighborhood facilities for activity & 5-point Likert scale & & $0.70-0.80$ \\
\hline (4) Pre-PAQ Levels 1-2 & Mins.day ${ }^{-1}$ & 0.44 & \\
\hline (5) Pre-PAQ Level 3 & Mins.day ${ }^{-1}$ & 0.53 & \\
\hline (6) Pre-PAQ Level 4 & Mins.day ${ }^{-1}$ & 0.44 & \\
\hline (7)Pre-PAQ Level 5 & Mins.day ${ }^{-1}$ & 0.64 & \\
\hline
\end{tabular}

difference between the questionnaire and accelerometer measures was 45.2 mins.day ${ }^{-1}$. The mean difference between the two accelerometer categorizations (Reilly et al's non sedentary activity compared with Sirard et al's LMVPA) was 26.0 mins.day ${ }^{-1}$.

Agreement between Pre-PAQ Levels 1-2 and sedentary level of activity was poor whether this level was defined using Sirard et al's (mean difference -235.4 mins.day ${ }^{-1}$ ) or Reilly et al's (mean difference -208.6 mins.day ${ }^{-1}$ ) cut-points. When the categorization of accelerometer data was modified to denote stationary time (count range: 0-20), then level of agreement improved considerably (mean difference 7.6 mins.day $^{-1}$ ) although the limits of agreement were still wide (95\% LoA, -141.3 to 156.4 mins.day ${ }^{-1}$ ).

Differences vs. mean plots of light activity (Pre-PAQ Level 3 and LPA), and moderate to fast activity (PrePAQ Levels 4-5 and MVPA) indicated a bias towards over-reporting by Pre-PAQ of activity time beyond certain thresholds (Figure 2). Parent report of child activity was most closely aligned with accelerometer data when the reported time on the Pre-PAQ was between 40 and 80 minutes for light activity and between 40 and 75 minutes for moderate to fast activity. The difference vs. mean plots show a systematic error in which the overestimate of activity time on the Pre-PAQ became larger as

Table 5 Level of agreement of time spent in the different levels of activity between Pre-PAQ and accelerometer ${ }^{1}$

\begin{tabular}{|c|c|c|c|c|c|}
\hline $\begin{array}{l}\text { Pre-PAQ } \\
\text { categorisation } \\
\text { (level) }\end{array}$ & $\begin{array}{l}\text { Accelerometer } \\
\text { categorisation }\end{array}$ & $\begin{array}{l}\text { Mean } \\
\text { difference } \\
\left(\text { mins.day }^{-1}\right)^{1}\end{array}$ & $\begin{array}{l}\text { Lower limit of } \\
\text { agreement }\end{array}$ & $\begin{array}{l}\text { Upper limit of } \\
\text { agreement }\end{array}$ & $\begin{array}{l}\text { Correlation } \\
\text { (r) }\end{array}$ \\
\hline Level 1-2 & Stationary & 7.6 & -141.3 & 156.4 & $0.25^{*}$ \\
\hline Level 1-2 & Sedentary (Reilly) & -208.6 & -349.8 & -67.5 & $0.28^{*}$ \\
\hline Level 1-2 & Sedentary (Sirard) & -235.4 & -383.1 & -87.7 & 0.19 \\
\hline Level 3 & LPA (Sirard) & -4.8 & -105.4 & 96.0 & -0.07 \\
\hline Level 4 & MPA (Sirard) & 48.2 & -24.9 & 121.3 & 0.13 \\
\hline Level 5 & VPA (Sirard) & 1.9 & -37.5 & 41.3 & 0.17 \\
\hline Level 4-5 & MVPA (Sirard) & 50.1 & -42.9 & 143.1 & 0.17 \\
\hline Level 3-5 & Non-sedentary (Reilly) & 20.9 & -121.9 & 163.7 & 0.16 \\
\hline Level 3-5 & LMVPA (Sirard) & 45.2 & -103.6 & 194.1 & 0.05 \\
\hline
\end{tabular}

3-Day mean

*Significant at 0.05 level. 


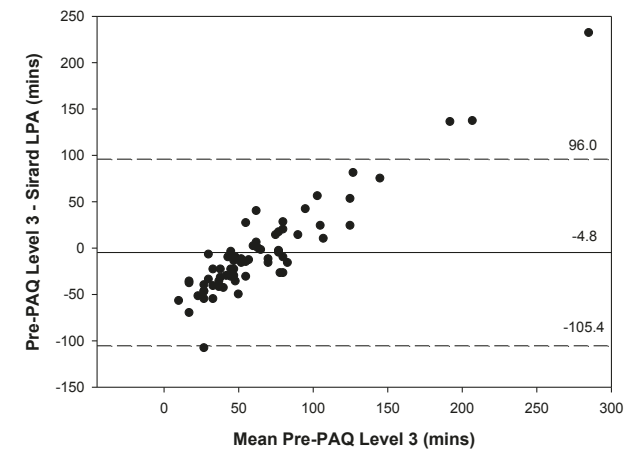

A: Mean Pre-PAQ Level 3 vs Sirard LPA

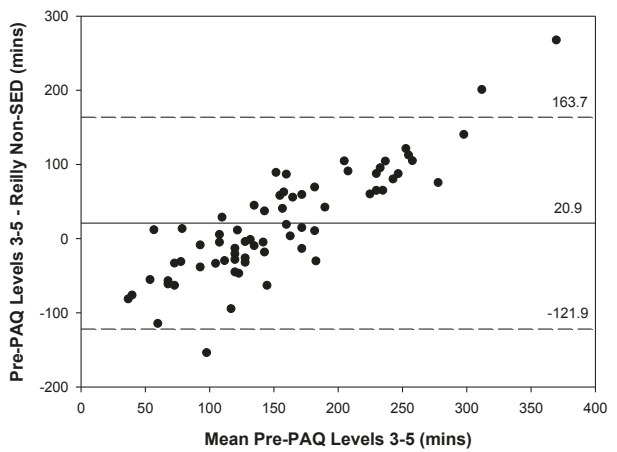

C: Mean Pre-PAQ Levels 3-5 vs Reilly Nonsedentary

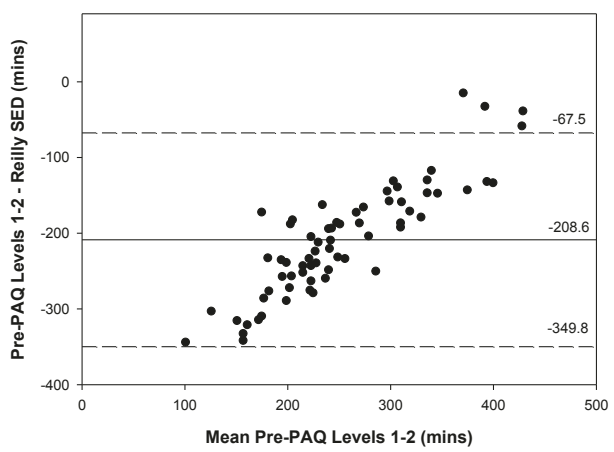

E: Mean Pre-PAQ Levels 1-2 vs Reilly Sedentary

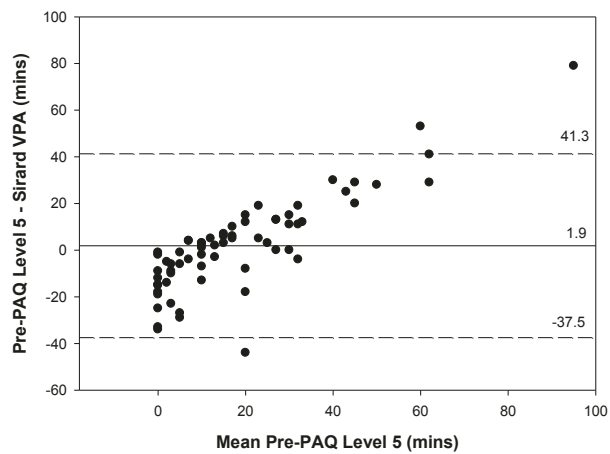

B: Mean Pre-PAQ Level 5 vs Sirard VPA

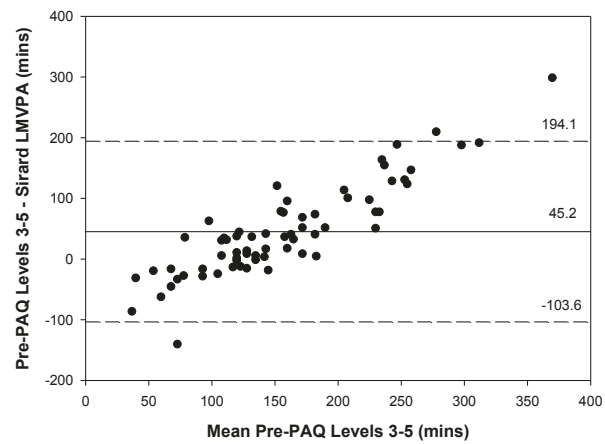

D: Mean Pre-PAQ Levels 3-5 vs Sirard LMVPA

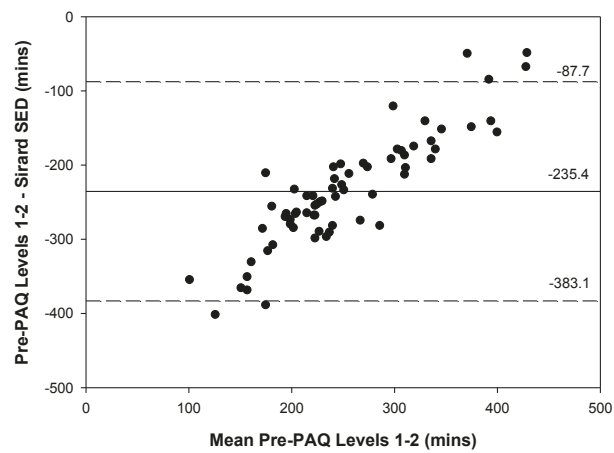

F: Mean Pre-PAQ Levels 1-2 vs Sirard Sedentary

Figure 2 Modified-Bland Altman plots depicting mean bias and limits of agreement between Pre-PAQ and accelerometer estimates of physical activity.

the magnitude of reported time increased. This pattern of reporting bias was also evident with fast activity (PrePAQ Level 5) particularly when reported Pre-PAQ Level 5 time was greater than 30 minutes.

\section{Discussion}

Physical activity is a complex behavior and no perfect criterion measure exists [8,31]. In this study we assessed young children's activity using two assessment methods 
- (a) accelerometry (using two commonly accepted approaches to categorizing activity) and (b) proxy (parent) reporting on the newly developed Pre-PAQ questionnaire, in order to ascertain the validity of the latter. Pre-PAQ and accelerometry have different features in estimating the duration of physical activity levels in children. We accepted that there would be differences between the two measures because of the difference in the properties of the tools. Nonetheless, the results indicate that Pre-PAQ has moderate to very good reliability and acceptable validity detailed below.

\section{Reliability}

Reliability coefficients on items relating specifically to the child's activity behavior, which largely represented time spent in free play or unstructured activity, ranged from moderate to good agreement for time spent in the four activity levels (Pre-PAQ Levels 1-2, 3, 4 and 5). There was very good test-retest reliability for involvement in organized activity and time spent in organized activities. This pattern of variation, with lower test-retest reliability estimates of free activity behavior compared with organized activity, has also been reported for older children [31,32]. In the older age groups, differences in reliability of activity estimates were considered acceptable because of presumed week-to-week variation in free activities, a situation that is equally applicable to young children. Thus, the test-retest differences in activity participation in this study may simply reflect real changes in activity behavior and not respondent error.

The findings of this study suggest that parent behavior was reported consistently over the two administrations of Pre-PAQ. A similar pattern of reliability in adult activity behavior was reported by Brown et al using the Active Australia Survey (AAS) in a study of middle-aged Australian women [33] and in a general adult Australian population [34]. The adult activity questions in PrePAQ were drawn from the AAS and the comparative results between this study and those of Brown et al suggest that the reliability of this section of Pre-PAQ is consistent with the original and modified (self-administered) versions of the AAS.

Variation in test-retest reliability was noted for reported car time. There was good agreement during weekdays but lower response consistency for car time on Saturday or Sunday. It is feasible that for most families, car use varies more on weekends than on week days, and thus the difference in reported car use may again reflect actual behavior changes.

Items relating to potential influences upon the child's activity behavior, such as parenting behaviors and attitudes, neighborhood safety and walkability, and a number of SSR items in the household, showed good to very good reliability. One would anticipate stability in these factors in the 1-2 week time frame.

\section{Validity}

The level of agreement between Pre-PAQ and accelerometry varied between different activity levels. The measures were closest when assessing either fast-paced (mean difference: 1.9 mins.day ${ }^{-1}$ ) or slow-paced movement (mean difference: -4.8 mins.day ${ }^{-1}$ ). In assessing total activity the mean difference ranged between 20.9 mins.day ${ }^{-1}$ (using Reilly's cut-points) and 45.3 mins.day $^{-1}$ (using Sirard's cut-points). The mean difference between the two objective measures for total activity was 26.0 mins.day ${ }^{-1}$. These findings suggest that Pre-PAQ has adequate validity as a population measure of physical activity. However the $95 \%$ limits of agreement were wide in each of these comparisons. Thus, while PrePAQ has acceptable agreement with accelerometer estimation of activity at a group level of behavior, caution should be applied in using the tool as a measure of an individual's behavior.

Pre-PAQ has better validity as a measure of physical activity rather than of sedentary behavior, as defined using the cut-points of Reilly et al [26] or Sirard et al [25]. The level of agreement between Pre-PAQ Levels 12 (stationary activities) and sedentary level of activity was poor. While it is well-recognized that respondents tend to under-report sedentary activities $[35,36]$, the type of data generated using accelerometry is also a potential issue for the difference in agreement. Accelerometer data include episodes of incidental behavior (e.g. pausing for momentary conversations, toileting routines etc.). Such activities are part of every-day life and would not constitute unhealthy sedentary behavior, nor are they captured by questionnaire activity recall.

The study findings may also be influenced by the choice of accelerometry cut-points. The sedentary cutpoints that we used included both low levels of activity, as well as completely stationary behavior (Sirard cutpoints: 0-301 for 3 year olds, 0-363 for 4 year olds and 0-398 for 5 year olds [25], and Reilly cut-points: 0-275 for 3-5 year olds [26]). When accelerometer data were re-categorized using 0-20 counts as the cut-point for stationary activity, as opposed to sedentary activity, then the mean difference between these measures was only 7.6 mins.day ${ }^{-1}$. This suggests that Pre-PAQ is a valid measure of stationary activity. However, at present the cut-point for denoting stationary behavior is a theoretical construct based upon the manufacturer's advice on the Actigraph 7164 accelerometer model's sensitivity to detect movement. As noted earlier, the findings of Krishnaveni et al [27] do lend support of this theoretical cut-point. Further confirmation of the cut-point using 
direct observation as the comparative measure is warranted.

Pre-PAQ provides important contextual information about specific sedentary behaviors such as television viewing time, habit of eating in front of the television, and use of electronic media. These behaviors are problematic in older children and adults in terms of health outcomes compared with other light-level activities [37]. A better understanding of these specific behaviors is crucial to identify optimal habits in preschool-age children. Such important contextual information cannot be ascertained by accelerometry.

The differences vs. means plots (see Figure 2) show a systematic error in which the overestimate of activity time on the Pre-PAQ becomes larger as the magnitude of reported time increases. This pattern of bias between self-report questionnaires and accelerometry measures has also been reported in other validated self-report and proxy-report questionnaires designed for children $[31,38,39]$. In reporting activity (Pre-PAQ Levels 3-5), agreement with behavior measured by accelerometry is closest when the reported activity time is between 60120 minutes. Beyond 180 minutes there is a sharp positive bias towards over-reporting of the child's activity. This finding would suggest that if respondents do report $>180$ minutes of activity for their child (using PrePAQ) then the relationship between questionnaire data and accelerometry should be questioned.

A recent systematic review of physical activity validation studies in children aged $\leq 19$ years reported low to moderate associations between the direct and indirect activity measures [40]. Correlation coefficients reported for studies using only accelerometry and questionnaires (self-report) ranged widely (from 0.03 to 0.76). In the current study, the correlation between Pre-PAQ and accelerometry was low for all levels of activity.

The results are, however, at least comparable to other proxy-report questionnaires used in a similar age group or slightly older children (see Table 6). For example, the proxy report version of the Children's Leisure Activity Study Survey, used for children aged 5-7 years, had correlations of rho $=-0.06(\mathrm{MPA})$, rho $=-0.04(\mathrm{VPA})$, and rho $=-0.04$ (Total Physical Activity) with accelerometry [41]. The Children's Physical Activity Questionnaire, used in children aged 4-5 years, had correlations between $r=-0.24$ and -0.10 with accelerometry using 1952 counts and 3000 counts respectively as the lower threshold for MVPA [39]. These findings suggest that Pre-PAQ is as robust as other questionnaires used in the same or slightly older age groups.

The findings of this study affirm that physical activity is a complex behavior and no perfect criterion measure exists $[8,31]$. Accelerometry and questionnaires both have strengths and limitations as measures of physical activity [10]. In this study, we have sought to identify how one measure relates to the other.

\section{Contextual information}

Pre-PAQ was designed under the premise that there are multidimensional influences upon young children's behavior, reflecting a socioecological framework. This premise is supported by others [14]. It should be emphasized that Pre-PAQ has been designed to measure physical activity in the home environment as young children spend much of their time in this environment and hence are subject to the influences within this environment. Thus, Pre-PAQ also includes information about parent activity behavior, parental attitudes related to child-rearing, background culture, family structure (number, age and sex of children), and the home and neighbourhood environment, including access to and use of facilities for organised activity. The responses to questions related to culture, family structure, and home and neighborhood environment were very consistent in the test-retest assessment of Pre-PAQ (ICC $(2,1)$ : 0.96$1.00 ; \kappa: 0.96-1.00$, \% agreement: 78.0-100.0). The contextual information provided by Pre-PAQ therefore should facilitate identification of factors associated with children's activity behavior.

\section{Limitations and modifications to Pre-PAQ}

The original version of this tool included sections that assessed the child's activity preference and motor skill proficiency. The study findings showed that responses to items in these sections had very good reliability $(\kappa=$ $0.70-1.00$, \% agreement $=80.6-100)$. However, the responses did not discriminate between the participants. In the section on activity preferences, parents generally reported that their child liked all the listed activities and hence this information did not assist in identifying whether activity preference influenced activity behavior. These items have been removed from the latest version of Pre-PAQ.

The motor skill proficiency items were drawn from the Ages and Stages Questionnaire, a parent-completed developmental assessment of children from birth to five years of age [42], the primary purpose of which is to identify children with developmental delay. The participants in this study were developmentally normal and consequently there was a ceiling level in this section of Pre-PAQ. The items therefore did not detect children with advanced motor skill proficiency, and hence we could not investigate the hypothesis that advanced motor skill proficiency might be associated with higher activity levels. This section has therefore also been removed from the latest version of Pre-PAQ.

In this study a convenience sample was used and the participants completed an English version of the 
Table 6 Comparison of the reliability and validity of Pre-PAQ with other young children's questionnaires validated using accelerometry (Actigraph)

\begin{tabular}{|c|c|c|c|}
\hline Tool, age group & Reliability & Validation & Correlation \\
\hline CAP Questionnaire [43]: self report & Three preferred activities: & Raw movt (total counts): - & $r=0.30$ \\
\hline \multirow[t]{2}{*}{ (4-9 years) } & $r=0.41$ & & \\
\hline & Test-retest interval: 2 weeks & & \\
\hline \multirow[t]{2}{*}{ CLASS [41]: proxy report } & MVPA: ICC $=0.49$ & MPA: - & rho $=-0.06$ \\
\hline & VPA: ICC = 0.81 & VPA: - & rho $=-0.04$ \\
\hline \multirow[t]{7}{*}{ (5-6 years) } & $\begin{array}{l}\text { Total PA: ICC }=0.76 \\
\text { (frequency) }\end{array}$ & Total PA: - & rho $=-0.04$ \\
\hline & & Raw movt. (counts.day ${ }^{-1}$ ): - & rho $=0.05$ \\
\hline & Percent agreement: & & \\
\hline & MPA: 84.2 & & NS \\
\hline & VPA: 58.6 & & \\
\hline & Total PA: 89.2 & & \\
\hline & Test-retest interval: 2 weeks & & \\
\hline CPAQ [39]: proxy report & MVPA: ICC $=0.39$ & Mean level of agreement & \\
\hline \multirow[t]{2}{*}{ (4-5 years) } & Test-retest interval: 1 week & MVPA $_{1952:}:-76.5$ mins.wk ${ }^{-1}$ & $r=-0.23$ \\
\hline & & MVPA $_{3000}:-235.9$ mins.wk ${ }^{-1}$ & $r=-0.10$ \\
\hline NPAQ [44]: proxy report & $\mathrm{NPAQ}_{\text {total }} \kappa=0.39$ & VPA > $2818\left(\right.$ mins.day $\left.{ }^{-1}\right):-$ & rho $=0.36$ \\
\hline \multirow[t]{3}{*}{ (Mean age in study: 5.7 years: age range not reported) } & $\mathrm{NPAQ}_{\text {total }}$ rho $=0.61$ & Total PA (counts. $\min ^{-1}$ ): - & rho $=0.33$ \\
\hline & $N P A Q_{\text {total }} R=0.70$ & & \\
\hline & Test-retest interval: 2-8 weeks & & \\
\hline Pre-PAQ: proxy report & & Mean level of agreement & \\
\hline \multirow[t]{10}{*}{ (3-5 years) } & Stationary: ICC $=0.44$ & Stationary: 7.6 mins.day $^{-1}$ & $r=0.25^{*}$ \\
\hline & Slow PA: ICC $=0.53$ & SED $_{\text {Sirard: }}$-266.5 mins.day ${ }^{-1}$ & $r=0.21$ \\
\hline & Mod PA: ICC = 0.44 & SED Reilly: -208.6 mins.day ${ }^{-1}$ & $r=0.28^{*}$ \\
\hline & Fast PA: ICC $=0.64$ & LPA $_{\text {sirard: }}-4.8$ mins.day ${ }^{-1}$ & $r=-0.07$ \\
\hline & Mod-Fast PA: ICC $=0.54$ & MPA $_{\text {sirard: }}: 48.2$ mins.day ${ }^{-1}$ & $r=0.13$ \\
\hline & Slow-Fast PA: ICC = 0.61 & VPA $_{\text {Sirard: }}: 1.9$ mins.day $^{-1}$ & $r=0.17$ \\
\hline & Test-retest interval: $1-2$ weeks & MVPA $_{\text {sirard: }} 50.1$ mins.day ${ }^{-1}$ & $r=0.17$ \\
\hline & & LMVPA $_{\text {sirard: }} 45.3$ mins.day ${ }^{-1}$ & $r=0.05$ \\
\hline & & Non-SED Reilly: 20.9 mins.day ${ }^{-1}$ & $r=0.16$ \\
\hline & & & ${ }^{*} P<0.05$ \\
\hline
\end{tabular}

CAP Questionnaire = Children's Activity Picture Questionnaire, CLASS = Children's Leisure Study Survey, CPAQ = Children's Physical Activity Questionnaire, Pre$\mathrm{PAQ}=$ Preschool-aged Children's Physical Activity Questionnaire, NPAQ = The Netherlands Physical Activity Questionnaire for Young Children, MPA = moderate physical activity, VPA = vigorous physical activity, SED = sedentary level of activity, SED $_{\text {Reilly }}$; sedentary level of activity using Reilly et al cut-point, SED sirard ; sedentary level of activity using Sirard et al cut-point, LPA = light physical activity, LPA $_{\text {sirard }}$; light physical activity using Sirard et al cut-point, MPA Sirard $_{\text {, }}$

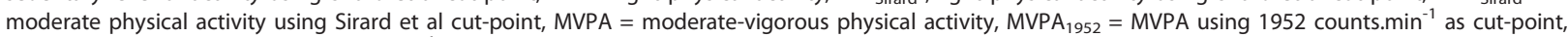
MVPA $_{3000}=$ MVPA using 3000 counts. $\mathrm{min}^{-1}$ as cut-point, VPA physical activity, LMVPA sirard $=$ light-moderate-vigorous physical activity using Sirard et al cut-point, Non-SED Reilly $=$ non-sedentary activity using Reilly et al cutpoint, $r$ ho $/ r=$ correlation, $P=p$-value, $N S=$ not significant.

questionnaire. We cannot assume that the findings can be generalised to non-English speaking groups. Further investigation of the usefulness of the tool with other sociocultural groups is warranted. If similar validity and repeatability are found, this would enable cross-cultural activity comparisons of young children's behavior to be undertaken. Such national and international data are essential to establish the level of young children's physical activity that is necessary to ensure optimal health.

\section{Conclusions}

Pre-PAQ appears promising as a tool to measure activity behavior in large-scale population studies involving preschool-age children. Pre-PAQ generally has good to very good reliability. While Pre-PAQ has poor agreement with accelerometry in assessment of sedentary activity, a similar limitation has been noted for most questionnaires used to measure activity in older children and adults. On the other hand, it appears a reasonable measure of stationary activity, as a theoretical construct. Therefore it can be concluded that Pre-PAQ has adequate validity in comparison to other questionnaires used with children and youth, and appears promising as a population measure, but it requires further testing on a more broadly representative population to affirm this. 
The advantages of Pre-PAQ are that it provides summary data on the nature, level and duration of a child's activity behavior. The tool also provides contextual information about potential influences on the child's activity behavior, including parental, family and neighborhood factors. This type of information is essential to identify potentially modifiable factors that can inform public health interventions to increase activity. Pre-PAQ fills an important niche for researchers to measure levels of physical activity and sedentary behavior in populations of preschool-age children and concurrently to measure parental, family and neighborhood factors that influence these behaviors.

\section{Additional material}

Additional file 1: Pre-PAQ ${ }^{\Phi_{\circledast}}$ Questionnaire (as modified post assessment of its reliability and validity).

\section{Acknowledgements \\ This research was supported by a Coles Community Development Fund Grant. GMD was supported by an NHMRC Postgraduate Allied Health Research Scholarship.}

\section{Author details}

'Discipline of Physiotherapy, University of Sydney, Box 170 Lidcombe NSW 1825, Australia. ${ }^{2}$ Discipline of Paediatrics and Child Health, The Children's Hospital at Westmead, University of Sydney, Locked Bag 4001 Westmead NSW 2145, Australia. ${ }^{3}$ Prevention Research Collaboration, Level 2, K25 Medical Foundation Building, University of Sydney NSW 2006, Australia. ${ }^{4}$ Research Consultant (Biostatistician), c/- Discipline of Paediatrics and Child Health, The Children's Hospital at Westmead, Locked Bag 4001 Westmead NSW 2145, Australia.

\section{Authors' contributions}

GMD designed the questionnaire, conceived and conducted the study, and drafted the manuscript. LLH assisted with the design of the questionnaire and participated in the design of the study. JKP assisted with the design of the questionnaire and the study, and advised on the statistical analysis. LAB assisted with the design of the questionnaire, and participated in the design and coordination of the study. All authors read, modified and approved the final manuscript.

\section{Competing interests}

The authors declare that they have no competing interests.

Received: 9 February 2011 Accepted: 4 August 2011

Published: 4 August 2011

\section{References}

1. Ludwig DS: Childhood Obesity - The Shape of Things to Come. New England Journal of Medicine 2007, 357:2325-2327.

2. McGavock J, Sellers E, Dean H: Physical activity for the prevention and management of youth-onset type 2 diabetes mellitus: focus on cardiovascular complications. Diabetes \& Vascular Disease Research 2007, 4:305-310.

3. Rao G: Childhood obesity: highlights of AMA Expert Committee recommendations. American Family Physician 2008, 78:56-63.

4. Daniels SR, Jacobson MS, McCrindle BW, Eckel RH, Sanner BM: American Heart Association Childhood Obesity Research Summit: executive summary. Circulation 2009, 119:2114-2123.

5. Fulton JE, Burgeson CR, Perry GR, Sherry B, Galuska DA, Alexander MP, Wechsler H, Caspersen CJ: Assessment of physical activity and sedentary behavior in preschool-age children: priorities for research. Pediatric Exercise Science 2001, 13:113-126.

6. Oliver M, Schofield GM, Kolt GS: Physical activity in preschoolers: understanding prevalence and measurement issues. Sports Medicine 2007, 37:1045-1070.

7. Tucker P: The physical activity levels of preschool-aged children: A systematic review. Early Childhood Research Quarterly 2008, 23:547-558.

8. Troiano RP: Can there be a single best measure of reported physical activity? American Journal of Clinical Nutrition 2009, 89:736-737.

9. Booth M: Assessment of physical activity: an international perspective. Research Quarterly for Exercise \& Sport 2000, 71:S114-120.

10. Montoye H, Kemper HCG, Saris WHM, Washburn RA: Measuring physical activity and energy expenditure Champaign, IL: Human Kinetics; 1996.

11. Sallis JF, Owen N: Physical activity and behavioral medicine Thousand Oaks, CA: Sage; 1999.

12. Australasian Child and Adolescent Obesity Research Network. [http:// sydney.edu.au/medicine/acaorn/].

13. Brown WH, Pfeiffer KA, Mclver KL, Dowda M, Addy CL, Pate RR: Social and environmental factors associated with preschoolers' nonsedentary physical activity. Child Development 2009, 80:45-58.

14. Hinkley T, Crawford D, Salmon J, Okely A, Hesketh K: Preschool children and physical activity: a review of correlates. American Journal of Preventive Medicine 2008, 34:435-441.

15. Loprinzi PD, Trost SG, Loprinzi PD, Trost SG: Parental influences on physical activity behavior in preschool children. Preventive Medicine 2010, 50:129-133.

16. Timperio A, Salmon J: Physical Activity Monitoring \& Evaluation Toolkit. Burwood, Victoria: Centre for Physical Activity \& Nutrition Research (C-PAN), School of Health Sciences, Deakin University; 2003.

17. Burdette HL, Whitaker RC: A national study of neighborhood safety, outdoor play, television viewing, and obesity in preschool children. Pediatrics 2005, 116:657-662.

18. Tucker $P$, Gilliland J: The effect of season and weather on physical activity: a systematic review. Public Health 2007, 121:909-922.

19. Puhl J, Greaves K, Hoyt M, Baranowski T: Children's Activity Rating Scale (CARS): description and calibration. Research Quarterly for Exercise \& Sport 1990, 61:26-36.

20. DuRant RH, Baranowski T, Puhl J, Rhodes T, Davis H, Greaves KA, Thompson WO: Evaluation of the Children's Activity Rating Scale (CARS) in young children. Medicine \& Science in Sports \& Exercise 1993, 25:1415-1421.

21. Peat JK, Mellis C, Williams K, Xuan W: Health science research: a handbook of quantitative methods Sydney: Allen \& Unwin; 2001.

22. Cliff DP, Reilly JJ, Okely AD: Methodological considerations in using accelerometers to assess habitual physical activity in children aged 0-5 years. Journal of Science \& Medicine in Sport 2009, 12:557-567.

23. Pate RR, O'Neill JR, Mitchell J: Measurement of physical activity in preschool children. Medicine \& Science in Sports \& Exercise 2010, 42:508-512.

24. Treuth MS, Sherwood NE, Baranowski T, Butte NF, Jacobs DR Jr, McClanahan B, Gao S, Rochon J, Zhou A, Robinson TN, Pruitt L, Haskell W, Obarzanek E: Physical activity self-report and accelerometry measures from the Girls health Enrichment Multi-site Studies. Preventive Medicine 2004, 38(Suppl):S43-49

25. Sirard JR, Trost SG, Pfeiffer KA, Dowda M, Pate RR: Calibration and evaluation of an objective measure of physical activity in preschool children. Journal of Physical Activity and Health 2005, 3:345-357.

26. Reilly JJ, Coyle J, Kelly L, Burke G, Grant S, Paton JY: An objective method for measurement of sedentary behavior in 3- to 4-year olds. Obesity Research 2003, 11:1155-1158.

27. Krishnaveni GV, Mills IC, Veena SR, Wootton SA, Wills AK, Coakley PJ, Fisher DJ, Shobha S, Karat SC, Fall CH, Fall CHD: Accelerometers for measuring physical activity behavior in Indian children. Indian Pediatrics 2009, 46:1055-1062.

28. Altman DG: Inter-rater agreement. In Practical Statistics for Medical Research. Edited by: Altman DG. London: Chapman 1991:403-409.

29. Bland JM, Altman DG: Statistical methods for assessing agreement between two methods of clinical measurement. Lancet 1986, 1:307-310.

30. Patterson P: Reliability, validity, and methodological response to the assessment of physical activity via self-report. Research Quarterly for Exercise \& Sport 2000, 71:S15-20 
31. Welk GJ, Wickel E, Peterson M, Heitzler CD, Fulton JE, Potter LD: Reliability and validity of questions on the youth media campaign longitudinal survey. Medicine \& Science in Sports \& Exercise 2007, 39:612-621.

32. Wong SL, Leatherdale ST, Manske SR: Reliability and validity of a schoolbased physical activity questionnaire. Medicine \& Science in Sports \& Exercise 2006, 38:1593-1600.

33. Brown WJ, Burton NW, Marshall AL, Miller YD: Reliability and validity of a modified self-administered version of the Active Australia physical activity survey in a sample of mid-age women. Australian \& New Zealand Journal of Public Health 2008, 32:535-541.

34. Brown WJ, Trost SG, Bauman A, Mummery K, Owen N: Test-retest reliability of four physical activity measures used in population surveys. Journal of Science \& Medicine in Sport 2004, 7:205-215.

35. Bryant MJ, Lucove JC, Evenson KR, Marshall S: Measurement of television viewing in children and adolescents: a systematic review. Obesity Reviews 2007, 8:197-209.

36. Clark BK, Sugiyama T, Healy GN, Salmon J, Dunstan DW, Owen N: Validity and reliability of measures of television viewing time and other nonoccupational sedentary behaviour of adults: a review. Obesity Reviews 2009, 10:7-16

37. Rey-Lopez JP, Vicente-Rodriguez G, Biosca M, Moreno LA: Sedentary behaviour and obesity development in children and adolescents. Nutrition Metabolism \& Cardiovascular Diseases 2008, 18:242-251.

38. Anderson $C B$, Hagstromer $M$, Yngve A: Validation of the PDPAR as an adolescent diary: effect of accelerometer cut points. Medicine \& Science in Sports \& Exercise 2005, 37:1224-1230.

39. Corder K, van Sluijs EMF, Wright A, Whincup P, Wareham NJ, Ekelund U: Is it possible to assess free-living physical activity and energy expenditure in young people by self-report? American Journal of Clinical Nutrition 2009, 89:862-870.

40. Adamo KB, Prince SA, Tricco AC, Connor-Gorber S, Tremblay M: A comparison of indirect versus direct measures for assessing physical activity in the pediatric population: a systematic review. International Journal of Pediatric Obesity 2009, 4:2-27.

41. Telford A, Salmon J, Jolley D, Crawford D: Reliability and validity of physical activity questionnaires for children: the Children's Leisure Activities Study Survey (CLASS). Pediatric Exercise Science 2004, 16:64-78.

42. Squires J, Potter L, Bricker D: The ASQ user's guide Baltimore, Maryland: Paul H. Brookes Publishing; 1999.

43. Parrish AM, Iverson D, Russell $K$, Yeatman $H$ : The development of a unique physical activity self-report for young children: challenges and lessons learned. Research in Sports Medicine 2010, 18:71-83.

44. Janz KF, Broffitt B, Levy SM: Validation Evidence for the Netherlands Physical Activity Questionnaire for Young Children: The lowa Bone Development Study. Research Quarterly for Exercise and Sport 2005, 76:363.

45. Australian Bureau of Statistics: Census of Population and Housing: SocioEconomic Indexes for Areas (SEIFA) 2001. Canberra: Commonwealth of Australia; 2003.

doi:10.1186/1479-5868-8-86

Cite this article as: Dwyer et al:: The validity and reliability of a home environment preschool-age physical activity questionnaire (Pre-PAQ). International Journal of Behavioral Nutrition and Physical Activity 2011 8:86.

\section{Submit your next manuscript to BioMed Central and take full advantage of:}

- Convenient online submission

- Thorough peer review

- No space constraints or color figure charges

- Immediate publication on acceptance

- Inclusion in PubMed, CAS, Scopus and Google Scholar

- Research which is freely available for redistribution 